adequate overall left ventricular filling, thus, resulting in LV diastolic dysfunction [6, 7]. The elegant experiments by SANTAMORE et al. [8] demonstrated that the diastolic properties of the left ventricle can be modified by changes in RV pressure and compliance even without a change in RV volume. Ventricular interdependence is defined as the forces that are transmitted from one ventricle to the other ventricle through the myocardium and pericardium, independent of neural, humoral, or circulatory effects [9]. This phenomenon is a consequence of the close anatomic association between the ventricles, the key role of the interventricular septum and the pericardial constraint and can explain the diastolic impairment of one ventricle in the presence of systolic impairment of the adjacent ventricle [10].

In conclusion, patients with idiopathic pulmonary fibrosis exhibit predominantly left ventricular diastolic dysfunction in addition to the expected impairment of right ventricular systolic and diastolic function. The presence of severe left ventricular systolic dysfunction should guide the clinician to search for other causes of left ventricular impairment.

\section{Bouros* and G. Giannakoulas ${ }^{\#}$}

*Dept of Pneumonology, Medical School, Democritus University of Thrace, Alexandroupolis, Greece, and "Royal Brompton Hospital, London, UK.

\section{STATEMENT OF INTEREST}

None declared.

\section{REFERENCES}

1 Louie EK, Lin SS, Reynertson SI, Brundage BH, Levitsky S, Rich S. Pressure and volume loading of the right ventricle have opposite effects on left ventricular ejection fraction. Circulation 1995; 92: 819-824.

2 Vizza CD, Lynch JP, Ochoa LL, Richardson G, Trulock EP. Right and left ventricular dysfunction in patients with severe pulmonary disease. Chest 1998; 113: 576-583.

3 Goto Y, Slinker BK, LeWinter MM. Nonhomogeneous left ventricular regional shortening during acute right ventricular pressure overload. Circ Res 1989; 65: 43-54.

4 Santamore WP, Gray L Jr. Significant left ventricular contributions to right ventricular systolic function. Mechanism and clinical implications. Chest 1995; 107: 1134-1145.

5 Krayenbuehl HP, Turina J, Hess O. Left ventricular function in chronic pulmonary hypertension. Am J Cardiol 1978; 41: 1150-1158.

6 Lazar JM, Flores AR, Grandis DJ, Orie JE, Schulman DS. Effects of chronic right ventricular pressure overload on left ventricular diastolic function. Am J Cardiol 1993; 72: 1179-1182.

7 Papadopoulos CE, Pitsiou G, Karamitsos TD, et al. Left ventricular diastolic dysfunction in idiopathic pulmonary fibrosis: a tissue Doppler echocardiographic study. Eur Respir J 2008; 31: 701-706.

8 Santamore WP, Constantinescu M, Vinten-Johansen J, Johnston WE, Little WC. Alterations in left ventricular compliance due to changes in right ventricular volume, pressure and compliance. Cardiovasc Res 1988; 22: 768-776.

9 Bove AA, Santamore WP. Ventricular interdependence. Prog Cardiovasc Dis 1981; 23: 365-388.

10 Parcharidou DG, Giannakoulas G, Efthimiadis GK, et al. Right ventricular function in ischemic or idiopathic dilated cardiomyopathy. Circ J 2008; 72: 238-244.

\title{
A new perspective on concepts of asthma severity, control and optimum treatment
}

\section{To the Editors:}

In their paper, TAYLOR et al. [1] outline a framework for asthma management for the years to come. The "perspective" may solve some of the problems experienced with the Global Initiative for Asthma [2-4]. Considering the enormous work behind the expert panel report [5] and the members of the panel, it is hard to imagine that every stone has not been turned. We are offered a framework or concept for managing asthma on an operational basis.

Complex systems develop when the factors involved are multiple, vary and interact, often in an unpredictable way. Asthma is a perfect example of a complex system, involving not only fluctuations in disease severity and treatment but also patient attitudes, including cross-cultural differences. Every step taken to reduce complexity in asthma management must be welcomed. In my opinion, the new perspective offers this. A further reduction of complexity may be achieved through defining the "optimum treatment" in an operational way.

The problem is that optimum treatment probably fluctuates and depends on not only asthma severity and type (i.e. allergic or primarily inflammatory or hyperreactive) but also on the characteristics of the patient and physician interacting in their partnership. Furthermore, the characteristics of the surrounding society might also have an impact on optimum treatment as what is considered optimum in some cultures cannot be afforded in others.

If the concept of optimum treatment could be operationalised, an algorithm for asthma treatment [6] might be achievable. With all respect, a working definition of optimum treatment might be "the minimal level of treatment which brings the 
asthma as close to control as possible and is acceptable to both the patient and physician".

"Minimal level" of treatment and the duration of the periods where asthma control is maintained need to be specified further. An algorithm of this type may fit well with a treatment principle where control is obtained rapidly and diagnosis confirmed in the first step. In the following steps, the treatment is optimised alongside with the education of the patient.

\section{F. Madsen}

Allergy and Lung Clinic Helsingør, Helsingør, Denmark.

\section{STATEMENT OF INTEREST}

None declared.

\section{REFERENCES}

1 Taylor DR, Bateman ED, Boulet LP, et al. A new perspective on concepts of asthma severity and control. Eur Respir J 2008; 32: 545-554.

2 National Heart, Lung, and Blood Institute. Asthma Management and Prevention: A Practical Guide for Public Health Officials and Health Care Professionals. 96-3659A. Bethesda, National Institutes of Health, 1995.

3 Global strategy for asthma management and prevention. www.ginasthma.com/Guidelineitem.asp??11=2\&12=1\&intId $=1561$ Date last accessed: January 15, 2009; Date last updated: 2008.

4 Bateman ED, Hurd SS, Barnes PJ, et al. Global strategy for asthma management and prevention: GINA executive summary. Eur Respir J 2008; 31: 143-178.

5 National Heart, Lung and Blood Institute. National Asthma Education and Prevention Program. Expert Panel. Report 3: Guidelines for the Diagnosis and Management of Asthma 2007. www.nhlbi.nih.gov/guidelines/asthma/asthgdln.htm Date last accessed: January 15, 2009; Date last updated: August 2007.

6 Madsen F, Sorensen HJ, Kallerup H. Global initiative for asthma. Problems with the logic of GINA experienced during the transformation of GINA to an operational algorithm. Am J Respir Crit Care Med 1997; 155: A891.

DOI: $10.1183 / 09031936.00148608$

\section{To the Editors:}

We welcome the important article delineating the difference between severity and control in asthma [1], but we wonder if, on reflection, a different nomenclature, with a broader scope, might be more useful in real life clinical practice. The authors' propose subgroups of severe asthma, where poor control for extraneous reasons (for example medication issues and/or associated co-morbidities) are included, although it was correctly pointed out that the term "severe" asthma should be reserved for those with a requirement for high intensity treatment. Typically, asthmatics come to a specialist clinic because of failure to respond to high dose therapy and, as discussed, there are many reasons for this.
We have proposed the umbrella term "problematic severe asthma" for these patients [2]. They may have either or both of poor baseline control and severe exacerbations. The first step is a detailed multidisciplinary assessment, if possible including a home visit, reviewing records of dispensed prescription and a psychological assessment. This initial assessment leads to about half the patients being placed in the "difficult" category [3]. Their problem (i.e. poor compliance) may not be easily resolved but they are clearly not candidates for potentially toxic therapies, such as cyclosporin or etanercept. The remainder then should have a detailed assessment of airway inflammation and an evaluation of the response to intramuscular triamcinolone (or another reliable method of administering corticosteroids which cuts out uncertainty of patient adherence) to determine steroid responsiveness. Most, but not all of this group, will turn out to be truly "severe, therapyresistant", whose exacerbations, poor baseline control or both, may need innovative therapies. Our view is that different names for specific categories will lead to a reduction in the current confusion in the literature which has been highlighted [1]. Our suggestion, shown in figure 1, emphasises the distinction between difficult-to-treat asthma and severe, therapy resistant asthma. In fact, the same concept applies at any level of asthma severity; poorly controlled asthma deserves consideration of the reason for the difficulty before costly treatment is increased.

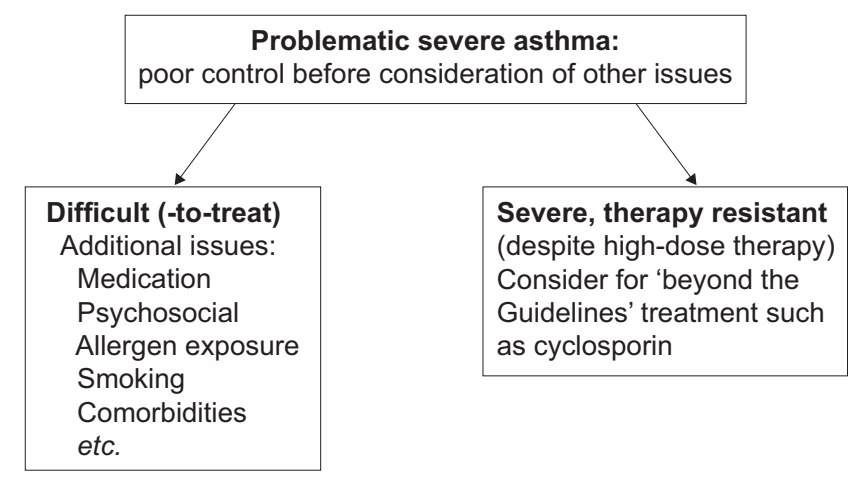

FIGURE 1. Suggested nomenclature of subgroups of problematic severe asthma.

\section{A. Bush*, F.M. de Benedictis ${ }^{+}$, G. Hedlin", J.Y. Paton", G. Wennergren ${ }^{\S}$ and N.M. Wilson*}

*Dept of Respiratory Paediatrics, Royal Brompton Hospital, London, and "Division of Developmental Medicine, University of Glasgow, Royal Hospital for Sick Children, Glasgow, UK. \#Astrid Lindgren Children's Hospital, Stockholm, and ${ }^{\S}$ Dept of Pediatrics, University of Gothenburg, Queen Silvia Children's Hospital, Göteborg, Sweden. ${ }^{+}$Division of Pediatrics, Salesi Children's Hospital, Ancona, Italy.

\section{STATEMENT OF INTEREST}

Statements of interest for F.M. de Benedictis and G. Wennergren can be found at www.erj.ersjournals.com $/ \mathrm{misc} /$ statements.shtml 